\title{
Investigations of the Anodic Porous Etching of n-InP in HCl by Atomic Absorption and X-ray Photoelectron Spectroscopies
}

\author{
Lionel Santinacci, ${ }^{1,2, *, z}$ Muriel Bouttemy, ${ }^{2}$ Matthieu Petit ${ }^{1}{ }^{1}$ Anne-Marie Gonçalves, ${ }^{2}$ \\ Nathalie Simon, ${ }^{2}$ Jackie Vigneron, ${ }^{2}$ and Arnaud Etcheberry ${ }^{2}$ \\ ${ }^{I}$ Aix-Marseille Univ., CNRS, CINaM, Marseille, France \\ ${ }^{2}$ Institut Lavoisier de Versailles (UMR CNRS 8180), Université de Versailles, Saint Quentin, France
}

\begin{abstract}
The electrochemical porous etching of $\mathrm{n}-\mathrm{InP}$ in $1 \mathrm{M} \mathrm{HCl}$ has been investigated by monitoring the mass of $\mathrm{In}^{3+}$ released during and after the anodic polarization. The study has been performed on both crystal-oriented (CO) and current line-oriented (CLO) pores grown at $10 \mathrm{~mA} \cdot \mathrm{cm}^{-2}$ and $5 \mathrm{~V}$ vs Ag/AgCl. An unexpected evolution of the mass of $\mathrm{In}^{3+}$ has been measured when the electrochemical dissolution process is stopped. It indicates a mass loss more than twice higher after 2 or 3 hours. This demonstrates that the accurate amount of dissolved InP must be considered a longtime after the end of the polarization. The comparisons of the etched masses for $\mathrm{CO}$ and CLO pores with the values calculated from the coulometric charges indicate that the etching processes are similar for the two pore geometries and that the dissolution valence for InP is 2 . The chemical analyses, performed by $\mathrm{X}$-ray photoelectron spectroscopy, reveal that the main corrosion products are $\mathrm{Cl}$-containing compounds such as $\mathrm{InCl}_{3}$. This gives valuable information to confirm an InP porous etching mechanism proposed earlier in literature.

(C) The Author(s) 2018. Published by ECS. This is an open access article distributed under the terms of the Creative Commons Attribution Non-Commercial No Derivatives 4.0 License (CC BY-NC-ND, http://creativecommons.org/licenses/by-nc-nd/4.0/), which permits non-commercial reuse, distribution, and reproduction in any medium, provided the original work is not changed in any way and is properly cited. For permission for commercial reuse, please email: oa@ electrochem.org. [DOI: 10.1149/2.0181804jes]
\end{abstract}

(cc) BY-NC-ND

Manuscript submitted November 6, 2017; revised manuscript received January 10, 2018. Published January 27, 2018. This paper is part of the JES Focus Issue on Processes at the Semiconductor-Solution Interface.

Likewise other one-dimensional nanostructures, electrochemically grown porous semiconductors have become an attractive field of interest. Though numerous attempts to understand the pore formation have been carried out, crucial mechanistic parameters such as the dissolution valence $(z)$ are still not clarified for III-V compounds since most of the studies refer to the porous etching of $\mathrm{Si}^{1}{ }^{1}$ Gravimetric investigations have pointed out different $z$ during electropolishing and pore formation on $\mathrm{Si}^{2}$ The dissolution valence is 4 (the expected value since $\mathrm{Si}$ is a tetravalent element) during electropolishing and it does not depend on the applied current density $(j)$, the doping or the electrolyte concentration $(c)$. Conversely, $z$ varies, from 2 to 4 , with those parameters during porous etching. Furthermore, the dissolution valence during the pore growth can be 4 at the tips and 2 on the walls. ${ }^{3}$ It illustrates that porous dissolution process is a tricky phenomenon and it is different from uniform polishing.

The pore growth mechanisms reported in literature can be divided in two families: "chemical" and "physical" models. The latter are based on the charge carrier distribution at the semiconductor/electrolyte interface and can basically be applied to any semiconductor since no chemical aspects are considered. However strong differences are observed between $\mathrm{Si}$, which is an elemental semiconductor, and III-V compounds or between III-V materials themselves. ${ }^{4}$ Thus chemical aspects must also be considered to depict accurately the porous dissolution of such materials. The peculiar dissolution along $\langle 111\rangle \mathrm{B}$ directions leading to crystal-oriented $(\mathrm{CO})$ pores in $\mathrm{GaP}, \mathrm{GaAs}$ and InP (with B referring to the second element for A-B compounds, e. g. $\mathrm{P}$ in $\mathrm{InP}$ and $\mathrm{GaP})^{5-7}$ or the catacomb-like pore morphology observed solely on $\mathrm{GaP}^{8}$ emphasizes the influence of the chemical nature of the semiconductors on the pore growth. The chemical aspect of the porous etching has also been evidenced by investigating the effect of the electrolyte composition, the solvent nature and the $\mathrm{pH}$. On InP or InSb, the pore morphology indeed changes depending on the nature of the halide in the solution $\left(\mathrm{F}^{-}, \mathrm{Cl}^{-}\right.$and $\left.\mathrm{Br}^{-}\right){ }^{9,10}$ An original coral-like geometry is observed when InP is etched in halide-containing liquid ammonia. ${ }^{11}$ The porous etching in strongly acidic (e. g. $\mathrm{HCl}$ or $\mathrm{HNO}_{3}{ }^{12}$ ) or alkaline (e.g. $\mathrm{KOH}^{13}$ ) solutions leads

*Electrochemical Society Member.

${ }^{\mathrm{z} E-m a i l: ~ l i o n e l . s a n t i n a c c i @ u n i v-a m u . f r ~}$ to different morphologies. For a longtime, porous films were grown at extreme $\mathrm{pH}$ (i. e. $\mathrm{pH}<2$ or $\mathrm{pH}>12$ ) while oxide layers were obtained for intermediate $\mathrm{pH} .{ }^{14,15}$ It has been recently demonstrated that porous dissolution can also be achieved at neutral solution in presence of $\mathrm{Cl}^{-} \cdot{ }^{16,17}$ Finally, a nucleophilic substitution mechanism has been proposed to explain the pore growth on III-V crystals. ${ }^{18-20}$ It demonstrates that both physical and chemical models must be considered when dealing with porous etching.

Investigations on the chemical, electrochemical and photoelectrochemical uniform etching of InP have led to various possible mechanisms. Although 6 or 8 charge mechanisms are usually admitted, the dissolution valence analytically determined by measuring the indium ion concentration in the etching solution, using atomic absorption spectroscopy (AAS) or inductively coupled plasma emission spectrometry (ICP-ES), varies from 3 to $12 . .^{22,23}$ Studies carried out by electrochemical impedance spectroscopy (EIS) have reported the real-time determination of $z$ during pore formation on $\mathrm{Si}$ and but not on InP. ${ }^{26}$ EIS can therefore be an alternative in situ measurement method of the dissolution valence but it requests a reliable model to accurately fit the acquired spectra. Finally, it has also been proposed to determine $z$ by measuring the mass loss using a very high precision balance before and after the etching process performed at neutral $\mathrm{pH}$ in $\mathrm{NaCl}^{16}$ In this case, it is not possible to monitor, in real-time, the dissolution process. Table I lists the different values of $z$ reported in literature during the past years for InP in various conditions using various investigation methods such as ICP-ES, AAS, gravimetry, coulometry and scanning electron microscopy (SEM). It demonstrates that the porous dissolution mechanism is still an opened question.

In a previous work, the porous etching process of $\mathrm{InP}$ in $\mathrm{HCl}$ has been studied from SEM examinations and AAS. ${ }^{24,27}$ Although it was difficult to calculate precisely the amount of dissolved InP from the SEM images, the AAS analyses have revealed an unexpected $\mathrm{In}^{3+}$ release after the anodization process that leads to a large increase of its concentration. These results were obtained on so-called current line oriented-pores (CLO) grown at constant potential of $5 \mathrm{~V}$. In the present report, the investigations have been carried out on the two pore morphologies: crystal-oriented (CO) and CLO pores. In the case of $\mathrm{CO}$ pores, it has even been possible to monitor the mass loss during the etching. Finally, after the comparison of the AAS results achieved on $\mathrm{CO}$ and CLO pores, the chemical composition of the porous layer 
Table I. Comparison of the dissolution valences for various etching conditions of InP.

\begin{tabular}{|c|c|c|c|c|c|}
\hline Doping type & Electrolyte & Etching process & Measurement method & $z$ & Ref. \\
\hline$n$ & Telluride in $\mathrm{KOH}$ & Uniform photoetching & Gravimetry & 6 or 8 & 21 \\
\hline$n$ & $\mathrm{HCl}, \mathrm{H}_{2} \mathrm{SO}_{4}, \mathrm{KOH} \ldots$ & Uniform and porous photoetching (CLO pores) & Coulometry, SEM & 6 & 18 \\
\hline$p$ & $\mathrm{HCl}$ and $\mathrm{HCl}$ in $\mathrm{CH}_{3} \mathrm{COOH}$ & Uniform etching & ICP-ES & 6 and 3 & 22 \\
\hline$n$ & $\mathrm{HCl}, \mathrm{H}_{2} \mathrm{SO}_{4}, \mathrm{KOH}_{\ldots}$. & Uniform photoetching & AAS & 6 & 23 \\
\hline$n$ & $\mathrm{NaCl}$ & CLO and CO pores & Coulometry & 4 to 8 & 16 \\
\hline$n$ & $\mathrm{HCl}$ & CLO pores & AAS, SEM & 8 & 24 \\
\hline$n$ & $\mathrm{KCl}$ & CLO and CO pores & Coulometry, SEM & 8 & 17 \\
\hline$n$ & $\mathrm{KOH}$ & CO pores & Coulometry, SEM & 6 & 25 \\
\hline
\end{tabular}

is analyzed by X-ray photoelectron spectroscopy (XPS) and the dissolution process is discussed with regard to a model previously reported.

\section{Experimental}

The porous layers were etched from $\mathrm{Sn}$ doped n-InP (100) wafers from InPact Inc. $\left(N_{\mathrm{Sn}} \approx 10^{18}\right.$ at $\left.\mathrm{cm}^{-3}\right)$ in analytical grade $1 \mathrm{M} \mathrm{HCl}$ deoxygenated and stirred by $\mathrm{N}_{2}$ bubbling. The samples were cleaved in $4 \times 4 \mathrm{~mm}^{2}$ square pieces and were cleaned with methanol. The porous etching was performed using a three electrode configuration in dark conditions. The InP sample, a Pt wire and an $\mathrm{Ag} / \mathrm{AgCl}$ $\left(U^{\circ}=236 \mathrm{mV}\right.$ vs. SHE) respectively served as working, counter and reference electrodes. The electrochemical dissolution was carried out either by applying a constant voltage $(U=5 \mathrm{~V}$, that corresponds to a stabilized current density of ca. $\left.1 \mathrm{~mA} \cdot \mathrm{cm}^{-2}\right)$ or a constant current density $\left(j=10 \mathrm{~mA} \cdot \mathrm{cm}^{-2}\right)$ using a PAR 173 potentiostat/galvanostat connected to a PAR 175 programmer.

Since AAS detection limit for indium is approximately hundred times higher than for phosphorus, the amount of dissolved InP was calculated from the $\mathrm{In}^{3+}$ concentration. It is, thus, assumed that the detected mass of In $(m)$ is equal to the quantity of etched InP. The concentration of the released $\mathrm{In}^{3+}$ was monitored by AAS before, during (when it was possible) and after the electrochemical dissolution. Fig. 1 illustrates the chronology of the sampling of the electrolyte. The quantity of indium in the solution was measured using a Thermo Scientific M6 atomic absorption spectrometer. Depending on the mass of $\mathrm{In}^{3+}$, the analyzer was set to flame $\left(c=1\right.$ to $\left.30 \mathrm{mg} \cdot \mathrm{L}^{-1}\right)$ or furnace $\left(c=50 \mu \mathrm{g} \cdot \mathrm{L}^{-1}\right)$ modes. Background corrections to the spectra were performed using a deuterium lamp and a Zeeman effect system for the flame and furnace modes, respectively. The calibration solutions were freshly prepared in a $1 \mathrm{M} \mathrm{HCl}$ reconstituted matrix. For flame analysis the air/acetylene flux was set to $0.9 \mathrm{~L} \cdot \mathrm{min}^{-1}$ and the burner position to $10.2 \mathrm{~mm}$. Furnace experiments were carried out with an extended lifetime cuvette, a working volume of $20-40 \mu \mathrm{L}$ and the following optimized operating parameters: $45 \mathrm{~s}$ drying at $110^{\circ} \mathrm{C}, 20 \mathrm{~s}$ ashing at

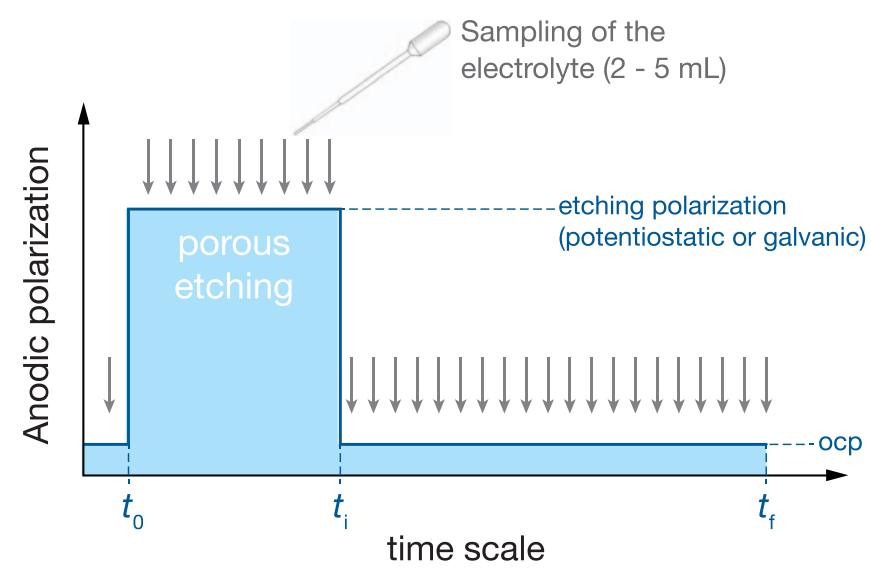

Figure 1. Schematic description of the method used to monitor the amount of released $\mathrm{In}^{3+}$. The gray arrows correspond to the sampling events. $950^{\circ} \mathrm{C}, 3 \mathrm{~s}$ atomization at $2300^{\circ} \mathrm{C}$ and $3 \mathrm{~s}$ cleaning at $2500^{\circ} \mathrm{C}$. Ascorbic acid and $\mathrm{Pd}\left(\mathrm{NO}_{3}\right)_{2}$ solutions were used as modifiers and automatically added to calibration and sample solutions by the autosampler in 1 to $4 \mu \mathrm{L}$ proportion for a $20 \mu \mathrm{L}$ working volume before analysis.

The chemical composition of the InP surface was analyzed by XPS before (reference) and after the porous etching. It was performed using a Thermo-VG-Escalab 220 iXL spectrometer. A focused monochromated X-ray beam $\left(\mathrm{Al} \mathrm{K} \mathrm{K}_{\alpha}\right)$ was used as excitation source while detection was performed using a constant analyzer energy with a threshold energy of $20 \mathrm{eV}$. The photoelectrons were collected perpendicularly to the surface. The morphology of porous layers was observed by SEM using a JEOL JSM 5800 microscope.

\section{Results and Discussion}

Pore morphologies.-It is well-known that the porous etching of InP leads to various morphologies. Fig. 2 shows a panel of different pore geometries obtained by applying various potentials or current densities. When a low current density $\left(j=1 \mathrm{~mA} \cdot \mathrm{cm}^{-2}\right)$ is applied for a relative short duration (200 s), CO pores are grown in triangular domains (Fig. 2a). This morphology has been initially observed in $\mathrm{KOH}^{28}$ but it appears also in acidic conditions in $\mathrm{HCl}$. For a higher current density $\left(j=10 \mathrm{~mA} \cdot \mathrm{cm}^{-2}\right)$ and a longer duration (500 s),
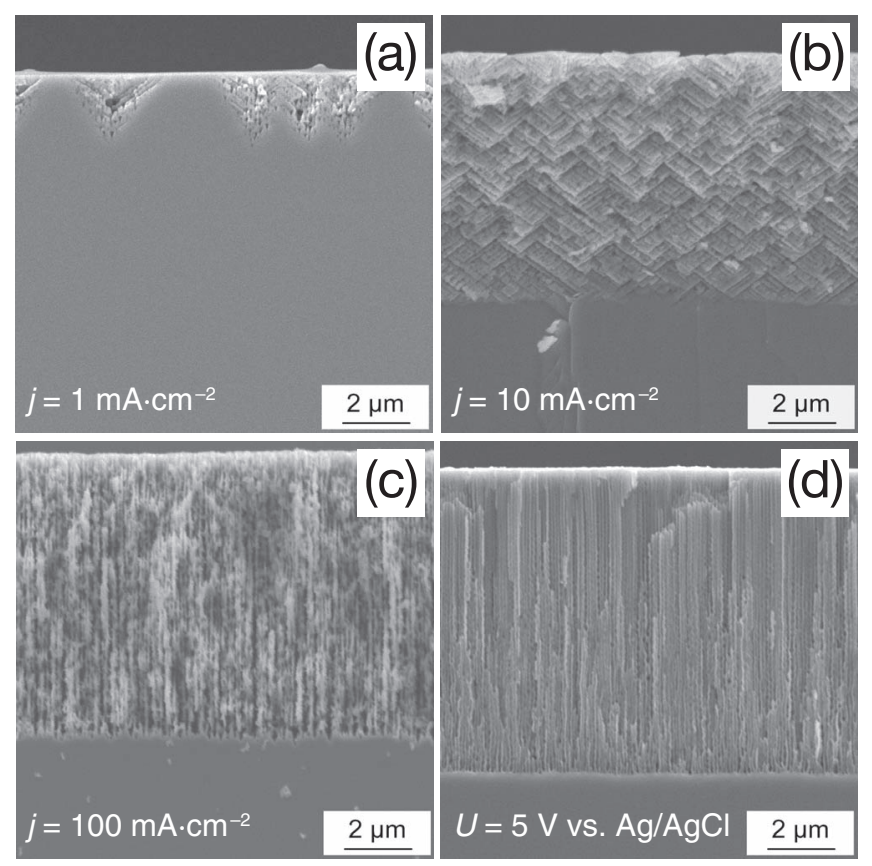

Figure 2. SEM cross sections of porous layers grown on n-InP in $1 \mathrm{M}$ $\mathrm{HCl}$ at (a) $j=1 \mathrm{~mA} \cdot \mathrm{cm}^{-2}$ for $200 \mathrm{~s}$, (b) $j=10 \mathrm{~mA} \cdot \mathrm{cm}^{-2}$ for $500 \mathrm{~s}$, (c) $j=100 \mathrm{~mA} \cdot \mathrm{cm}^{-2}$ for $50 \mathrm{~s}$ and (d) $U=5 \mathrm{~V}$ vs $\mathrm{Ag} / \mathrm{AgCl}$ for $10 \mathrm{~s}$. The corresponding anodic charges are $Q=0.2,0.5,5$ and $11.6 \mathrm{C} \cdot \mathrm{cm}^{-2}$, respectively. 


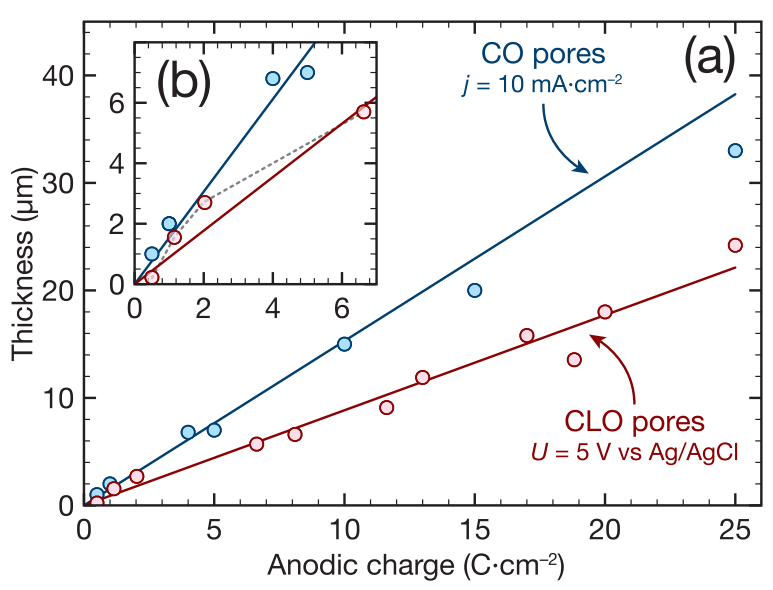

Figure 3. (a) Evolution of the thickness of the porous layer against the anodic charge for various etching conditions: CO pores at $j=10 \mathrm{~mA} \cdot \mathrm{cm}^{-2}$ and CLO pores at $U=5 \mathrm{~V}$ vs $\mathrm{Ag} / \mathrm{AgCl}$. (b) Inset showing an enlarged view of the evolution of $t_{\mathrm{p}}$ for low $Q$.

the CO pores cover whole surface. The typical dissolution channels along the $\langle 111\rangle$ direction are clearly visible on the SEM cross section presented in Fig. 2b. The CLO pore morphology is formed under stronger anodic polarizations. Fig. 2c and Fig. 2d show, respectively, the porous layers obtained under such conditions: $j=100 \mathrm{~mA} \cdot \mathrm{cm}^{-2}$ or $U=5 \mathrm{~V}$ vs $\mathrm{Ag} / \mathrm{AgCl}$, respectively. In those cases, the dissolution proceeds along the current lines, i. e., perpendicular to the surface and it seems that the polarization modes (galvanostatic or potentiostatic) have no significant influence on the pore morphology. In fact, the main parameter is the intensity of the applied polarization, i. e. the range of the external $j$ or $U$.

The thickness of the porous layer $\left(t_{\mathrm{p}}\right)$ has been measured from the SEM cross sections for both CO and CLO pores. Fig. 3a shows the evolution of $t_{\mathrm{p}}$ against the coulometric charge $(Q)$. As expected from literature, ${ }^{27}$ a linear evolution is observed in both cases. It suggests that the InP dissolution is directly related to the passed anodic charge and it indicates that the dissolution valence remains constant during the process. A different trend is, however, observed depending on the growth mode. The etch rate $\left(k_{\mathrm{t}}\right)$ for $\mathrm{CO}$ pores is significantly higher $\left(k_{\mathrm{t}}=1.5 \mu \mathrm{m} / \mathrm{C} \cdot \mathrm{cm}^{-2}\right)$ than for CLO pores $\left(k_{\mathrm{t}}=0.9 \mu \mathrm{m} / \mathrm{C} \cdot \mathrm{cm}^{-2}\right)$. This discrepancy can be explained either by a higher porosity $(p)$ in the CLO pores or by two different etching processes. The inset, Fig. 3b, presents an enlarged view of thickness evolution for the lowest charges. It shows a similar evolution in this range of $Q$ for $\mathrm{CO}$ and CLO pores because the nucleation layer of the CLO pores exhibits a $\mathrm{CO}$ morphology. In our preliminary work performed on CLO pores, ${ }^{24}$ it was possible to estimate the porosity from the SEM observations but such assessment on $\mathrm{CO}$ pores seems uncertain. In addition, the dissolution process could be different for CO and CLO morphologies. Chemical analyses appear therefore mandatory to compare the etching mechanisms of $\mathrm{CO}$ and CLO pores.

Chemical analyses by AAS. - The mass of $\mathrm{In}^{3+}$ released in the electrolyte has been monitored during and after the anodic polarization for CO and CLO pores grown respectively at $j=10 \mathrm{~mA} \cdot \mathrm{cm}^{-2}$ and $U=5$ V. Fig. 4 depicts the typical evolution of the mass of $\mathrm{In}^{3+}$ lost after the porous etching in $\mathrm{HCl}$. In order to facilitated the comparison, the curves presented in Fig. 4 corresponds to quasi similar anodic charges $\left(Q=2.9\right.$ and $2.5 \mathrm{C} \cdot \mathrm{cm}^{-2}$ for CO and CLO pores, respectively). In both cases, $m$ is unexpectedly not constant. It increases progressively with time and it reaches a plateau after 100 and $150 \mathrm{~min}$ for CLO and CO pores, respectively. This surprising behavior was already reported on CLO pores ${ }^{24}$ and Fig. 4 reveals that the release for $\mathrm{In}^{3+}$ follows a similar trend when a low polarization is applied (CO pores). It is important to mention here, that equivalent experiments have been performed on intact samples. After an immersion

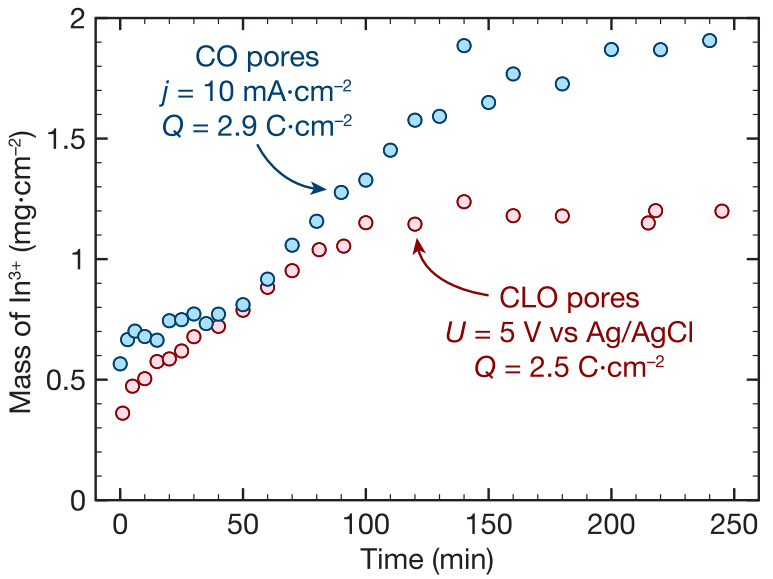

Figure 4. Evolution of the dissolved mass of $\mathrm{In}^{3+}$ with time for $\mathrm{CO}$ pores $\left(j=10 \mathrm{~mA} \cdot \mathrm{cm}^{-2}, Q=2.9 \mathrm{C} \cdot \mathrm{cm}^{-2}\right)$ and CLO pores $(U=5 \mathrm{~V}$ vs $\mathrm{Ag} / \mathrm{AgCl}$, $\left.Q=2.5 \mathrm{C} \cdot \mathrm{cm}^{-2}\right)$ in $1 \mathrm{M} \mathrm{HCl}(t=0$ correspond to the end of the anodic polarization).

of one week, in the same solution, only a negligible InP dissolution was detected. In addition, the SEM cross section obtained on porous layer after the full chemical analysis sequence confirms that the structure remains unchanged after a long dipping time. It demonstrates, therefore, that the increase of the $\mathrm{In}^{3+}$ amount arises from the electrochemical porous etching and not from an uncorrelated chemical dissolution. This validates that InP can only be chemically etched in highly concentrated $\mathrm{HCl}$ solutions $(c>5 \mathrm{M})$ because under such conditions $\mathrm{HCl}$ is not fully dissociated. ${ }^{22}$

In the present plot, the mass expansion ratio between $t_{\mathrm{i}}$ (just after the end of the polarization) and $t_{\mathrm{f}}$ (when the plateau is reached) is around 3 but for longer anodization times the ratio tends to 2 (see details thereinafter). Amid $t_{\mathrm{i}}$ and $t_{\mathrm{f}}$, the amount of $\mathrm{In}^{3+}$ increases almost linearly with the waiting time for the two pore geometries. The release delay can be explained by the lower density $(\rho)$ of the probable corrosion product such as $\mathrm{InCl}_{3}\left(\rho=4 \mathrm{~g} \cdot \mathrm{cm}^{-3}\right.$, respectively $\left.{ }^{29}\right)$ in comparison to InP $\left(\rho=4.81 \mathrm{~g} \cdot \mathrm{cm}^{-329}\right)$. The volume of matter that has to be extracted from the cavities after the dissolution reaction is, in those cases, much larger than the dissolved InP and it requests thus a long time to empty the channels. As seen on Figs. 4 and 5, the mass loss is slightly slower for $\mathrm{CO}$ pores and the plateau is reached

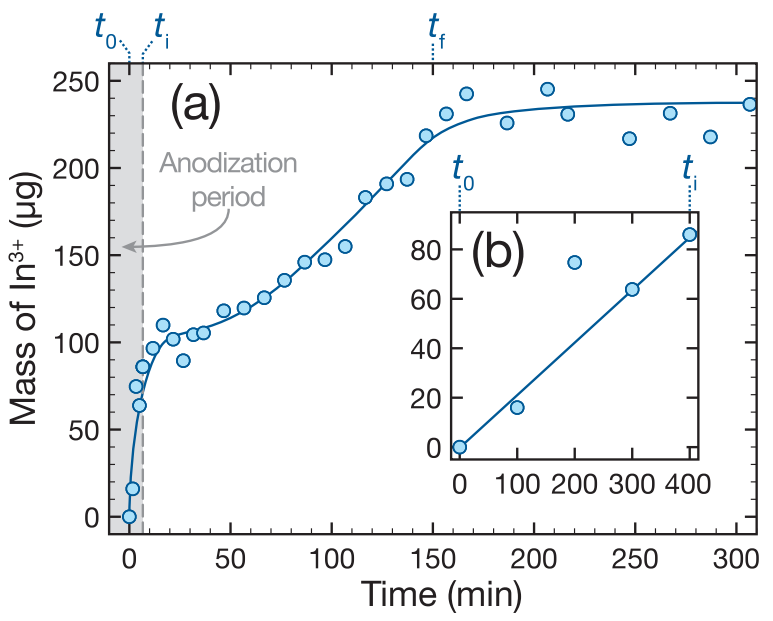

Figure 5. Evolution of the dissolved mass of $\mathrm{In}^{3+}$ with time (a) during and after the porous etching at $j=10 \mathrm{~mA} \cdot \mathrm{cm}^{-2}$ in $1 \mathrm{M} \mathrm{HCl}\left(Q=4 \mathrm{C} \cdot \mathrm{cm}^{-2}\right)$. The inset (b) shows the detail of the released $\mathrm{In}^{3+}$ amount during the pore formation. 

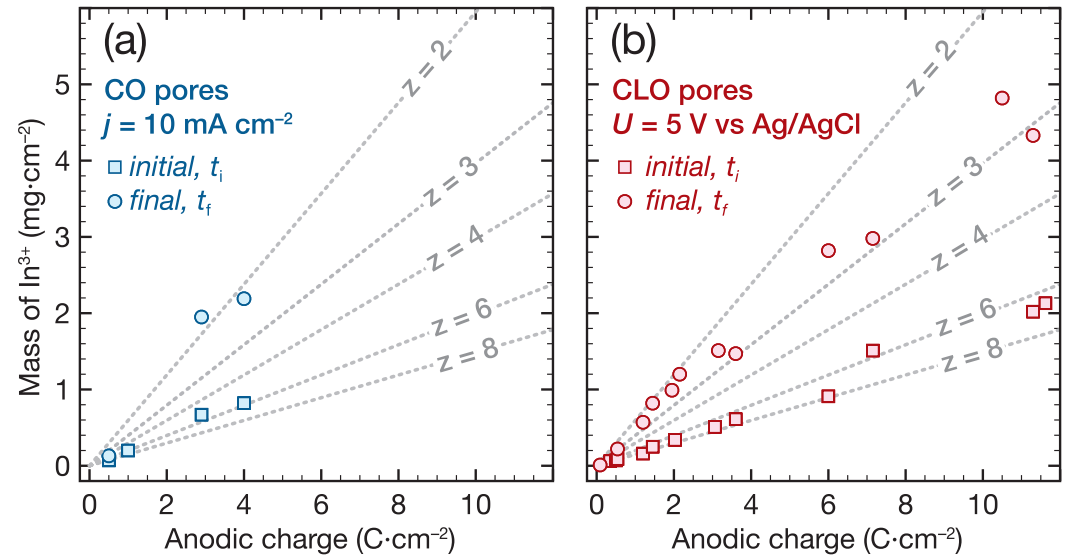

Figure 6. Evolution of the mass of $\mathrm{In}^{3+}$ released in the electrolyte with the anodic charge for $\mathrm{CO}$ (a) and CLO (b) pores. The mass of $\mathrm{In}^{3+}$ measured just after the polarization at $t_{\mathrm{i}}$ (circles) and on the plateau at $t_{\mathrm{f}}$ (squares) are compared to the calculated masses for $z=2,3,4,6,8$. after $t_{\mathrm{f}}=150 \mathrm{~min}$ while $100 \mathrm{~min}$ a requested for CLO pores. The difference of $t_{\mathrm{f}}$ between the two morphologies can be ascribed to the lower porosity of the $\mathrm{CO}$ pores, i. e. narrower channels, and thus it is more difficult to extract the products than for CLO pores. Note that a short initiation time (ca. $40 \mathrm{~min}$ ) where $m$ is almost constant, is even observed prior to the proportional $m$ increase for $\mathrm{CO}$ pores (Fig. 5). This confirms the difficulty to evacuate the byproducts in this pore morphology. Note also that quasi linear evolution of $m$ observed before $t_{\mathrm{f}}$ suggests a mass transport different than a planar diffusion. This is consistent with the pore diameter (less than $100 \mathrm{~nm}$ ). The unexpected $m$ variation after the end of the polarization indicates that the correct estimation of the amount of dissolved InP must be performed when the plateau is reached $\left(t \geq t_{\mathrm{f}}\right)$.

In comparison to the potentiostatic experiments, the duration of the galvanic treatments leading to $\mathrm{CO}$ pores, are longer because the applied current density is low $\left(j=10 \mathrm{~mA} \cdot \mathrm{cm}^{-2}\right)$. It allows therefore the monitoring of the mass of $\mathrm{In}^{3+}$ in the solution during the polarization. The general trend of $m$ vs. $Q$ is reported in Fig. 5a and the inset, Fig. 5b, shows the variation of the dissolved $\mathrm{In}^{3+}$ during the pore formation. This is the first report of an in situ measurement of the amount of In released while the porous etching takes place. A linear increase is again measured between $t_{0}$ (polarization start) and $t_{\mathrm{i}}$ (polarization end). It suggests a direct relation between the electrochemical process and the mass of dissolved material. As mentioned above, the variation of the $\mathrm{In}^{3+}$ after the polarization should be, however, taken into account to propose a correct dissolution mechanism. The evolution of the mass loss just after the anodic polarization $\left(t=t_{\mathrm{i}}\right)$ and when the plateau is reached $\left(t \geq t_{\mathrm{f}}\right)$ is thus plotted against the anodic charge for $\mathrm{CO}$ and CLO pores on Figs. 6a and 6b, respectively.

As expected from the curves plotted in Fig. 4 and Fig. 5, the mass of $\mathrm{In}^{3+}$ measured on the plateau $\left(m_{\mathrm{f}}\right)$ is significantly higher than the mass measured just at the end of the polarization $\left(m_{\mathrm{i}}\right)$. The evolutions of $m_{\mathrm{i}}$ and $m_{\mathrm{f}}$ against $Q$ for the two pore morphologies are presented in Fig. 6. At $t_{\mathrm{i}}$, a linear evolution is observed for both CO and CLO pores while at $t_{\mathrm{f}}$ the proportional trend is less pronounced. In order to analyze the experimental data, the mass of $\mathrm{In}^{3+}$ calculated from the coulometric charge $\left(m_{\mathrm{Q}}\right)$ using the Faraday's law (Eq. 1) is plotted on Fig. 6 for different valences $(z=2,3,4,6$ or 8$)$.

$$
m_{\mathrm{Q}}=\frac{Q \cdot M_{\mathrm{InP}}}{z \cdot F}
$$

In Eq. $1, M_{\text {InP }}$ and $F$ correspond to the molecular mass of InP and the Faraday's constant, respectively. The comparisons with the calculated $m_{\mathrm{Q}}$ indicate that the apparent valence, when the mass of $\mathrm{In}^{3+}$ is measured just after the polarization, is $z=6$. Although this value is in line with many reports (see Refs. in Table I), it is obviously not the correct data to describe the porous etching mechanism. The comparisons of $m_{\mathrm{f}}$ with the calculated $m_{\mathrm{Q}}$ suggest that the appropriate dissolution valence is closed to $z=2$ for the lower coulometric charges $\left(Q<4 \mathrm{C} \cdot \mathrm{cm}^{-2}\right)$ and is between 2 and 3 after. Despite the evident morphology differences between $\mathrm{CO}$ and CLO pores, it is surprising to observe the same evolutions for $m_{\mathrm{f}}$ on Figs. $6 \mathrm{a}$ and $6 \mathrm{~b}$. A similar etch rate $\left(k_{\mathrm{p}}=54 \mu \mathrm{g} / \mathrm{C} \cdot \mathrm{cm}^{-2}\right)$ is measured in both cases for $Q<4 \mathrm{C} \cdot \mathrm{cm}^{-2}$. The porosity is defined by the ratio between the volume of the dissolved matter $\left(V_{\mathrm{d}}\right)$ and the volume of the porous layer $\left(V_{\mathrm{p}}\right)$. The porosities of the CO and CLO pores, $p_{\mathrm{CO}}=10 \%$ and $p_{\text {CLO }}=16 \%$, respectively, are then deduced from $t_{\mathrm{p}}$ and $k_{\mathrm{p}}$. These values are lower than those reported in literature (e.g. $p_{\mathrm{CO}}=24 \%$ is reported for pores grown in $\mathrm{KOH}^{25}$ ). In the literature, $V_{\mathrm{d}}$ and $V_{\mathrm{p}}$ are calculated from the coulometric charges and the SEM cross sections. The dissolution valence is thus assumed and not calculated. In the present study, $V_{\mathrm{p}}$ is also deduced from the SEM micrographs because it provides a correct measurement of $t_{\mathrm{p}}$ but $V_{\mathrm{d}}$ is determined accurately from the AAS experiments without hypothesis on the $z$ value. It is thus a rigorous mean to identify the dissolution valence in addition to the porosity.

The similar $k_{\mathrm{p}}$ found in Fig. 6 for CO and CLO pores suggests identical porosities and analogous $t_{\mathrm{p}}$ evolutions. However the evolutions of $t_{\mathrm{p}}$ with $Q$ (see Fig. 3) show different rates for CO and CLO pores and the porosities $\left(p_{\mathrm{CO}}\right.$ and $\left.p_{\mathrm{CLO}}\right)$ are distinct. The qualitative analysis of the pore morphology performed from the SEM observation indicates that the pore diameters look indeed slightly different. The channels are narrower in CO pores than in CLO pores. Since a similar amount of InP is dissolved during the etching process, the geometry discrepancy arises from the pore density that should be higher in the $\mathrm{CO}$ morphology. The ratio $m_{\mathrm{f}} / m_{\mathrm{i}}$ is plotted against the anodic charges for the two morphologies in Fig. 7. As expected from the previous figures, the ratio tends to 2 for the high coulometric charges while it reaches almost 4 when $Q<4 \mathrm{C} \cdot \mathrm{cm}^{-2}$. At low $Q$, the polarization duration is generally short. Thus, there is less time to evacuate

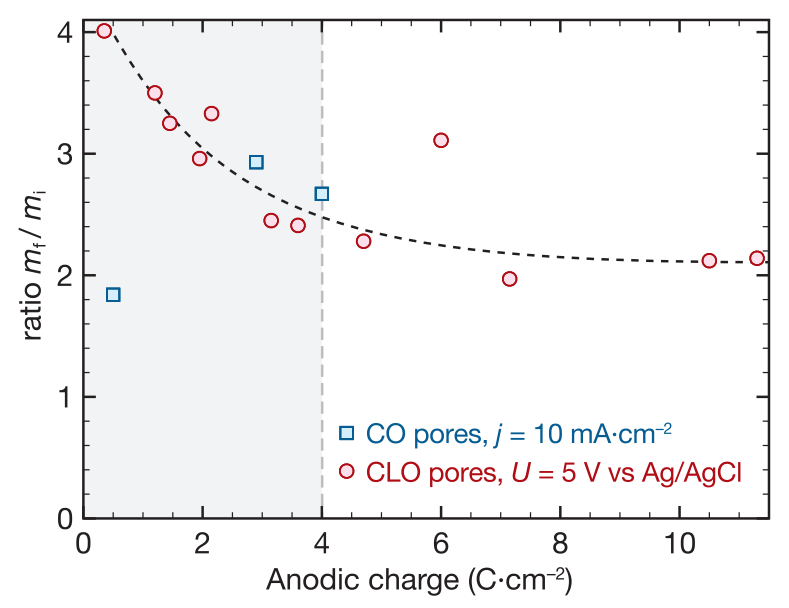

Figure 7. Ratio $\left(m_{\mathrm{f}} / m_{\mathrm{i}}\right)$ between initial and final masses of dissolved In for both $\mathrm{CO}$ and CLO pores. 


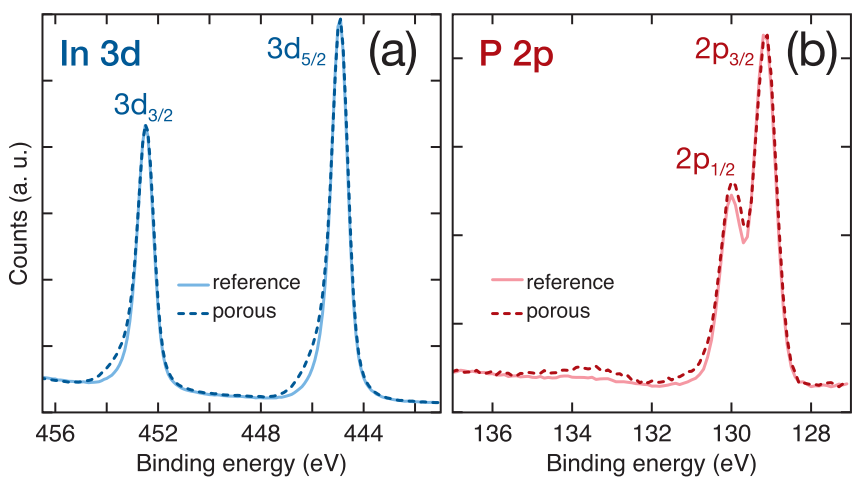

Figure 8. Comparison of the In $3 d$ (a) and P $2 p$ (b) XPS peaks measured on a deoxidized InP wafer (full lines) and a porous sample (dashed lines). The spectra have been normalized to facilitate the qualitative comparison of the spectroscopic signatures.

the dissolved matter while for higher anodic charges (i.e. longer polarization durations), a larger amount of corrosion products are extracted during the porous etching. In comparison to CLO pores, the ratio, for $\mathrm{CO}$ the geometry, does not reach high values because, again, the polarization takes longer. The normalized evolution of $m$ with $t$ has been plotted in a the previous work for CLO pores. It has revealed a quite uniform aspect of the curves but the plateau is indeed reached for shorter durations when the coulometric charge increases. According to this observations, the dissolution valence $(z \approx 2)$ is the same for the two morphologies. A similar dissolution mechanism occurs under low and high polarization conditions. The discrepancy between $k_{\mathrm{t}}$ observed in Fig. 3 is therefore ascribed to geometry difference and not to a distinct dissolution process.

Chemical composition by XPS.-The chemical composition of porous surface has been studied by XPS. The analyses evidence the presence of In and $\mathrm{P}$ as major elements with a $\mathrm{In} / \mathrm{P}$ ratio of 0.98 close to the expected one for an InP reference surface (1.0 to 1.1 XPS stoichiometry), a substantial $\mathrm{Cl}$ content $((\mathrm{In}+\mathrm{P}) / \mathrm{Cl}=6.57)$ as well as $\mathrm{C}$ and $\mathrm{O}$ mainly arising from inherent carbon contamination $(\mathrm{C} / \mathrm{O}=1.63)$ when transferring the sample from the electrolyte to the spectrometer. Fig. 8 shows the comparison of the In $3 \mathrm{~d}$ and P $2 p$ core level spectra obtained on a deoxidized InP blank wafer, considered as reference, and a sample etched at $5 \mathrm{~V}\left(Q=3.4 \mathrm{C} \cdot \mathrm{cm}^{-2}\right)$. Both are transferred and analyzed in the same experimental conditions. Small modifications of the In $3 \mathrm{~d}$ and $\mathrm{P} 2 \mathrm{p}$ peaks are observed. The In $3 \mathrm{~d}$ peak exhibits an slight enlargement of its bottom part at high energy and a minor oxide contribution (most probably due to the sample transfer) appears at $133.4 \mathrm{eV}$ in the $\mathrm{P} 2 \mathrm{p}$ region.

The high energy resolution spectra have been studied in more details and the peaks have been fitted using the spectroscopic parameters determined on the deoxidized InP reference sample. The results are presented in Fig. 9 with the initial assumption of a total evacuation of In and $\mathrm{P}$ materials dissolved during pore formation. The main spectral regions of the $\mathrm{P} 2 \mathrm{p}$ and $\mathrm{In} 3 \mathrm{~d}_{5 / 2}$ peaks are fitted considering two chemical environments in accordance with the observations made from Fig. 8. The major feature being associated to an InP network, "A" subscript writing, (P 2p spin orbit doublet at $129.1 \mathrm{eV}$ and In $3 \mathrm{~d}_{5 / 2}$ component at $444.9 \mathrm{eV}$ ), and the additional one, "B" subscript writing, being a specific signature of the porous system as discussed later. An additional feature $\mathrm{P} 2 \mathrm{p}_{\mathrm{ox}}$, related to the oxidized phosphorus, is also used to complete the $\mathrm{P} 2 \mathrm{p}$ window reconstruction. The corresponding $(\operatorname{In} / \mathrm{P})_{\mathrm{A}}$ and $(\mathrm{In} / \mathrm{P})_{\mathrm{B}}$ ratio calculated are very close, 0.97 and 1.08 , respectively. They are in line with the one obtained on the InP reference. This validates the fitting procedure. The $\mathrm{Cl} 2 \mathrm{p}$ region exhibits a main environment at $199.0 \mathrm{eV}\left(\mathrm{Cl} 2 \mathrm{p}_{\mathrm{B}}\right)$ whose binding energy is consistent with the presence of bonded chlorine-containing species at the probed InP surface. ${ }^{30}$ This is consistent with the presence of the additional $\mathrm{In}_{\mathrm{B}}$ and $\mathrm{P}_{\mathrm{B}}$ contributions. Their higher binding energy positions indi-
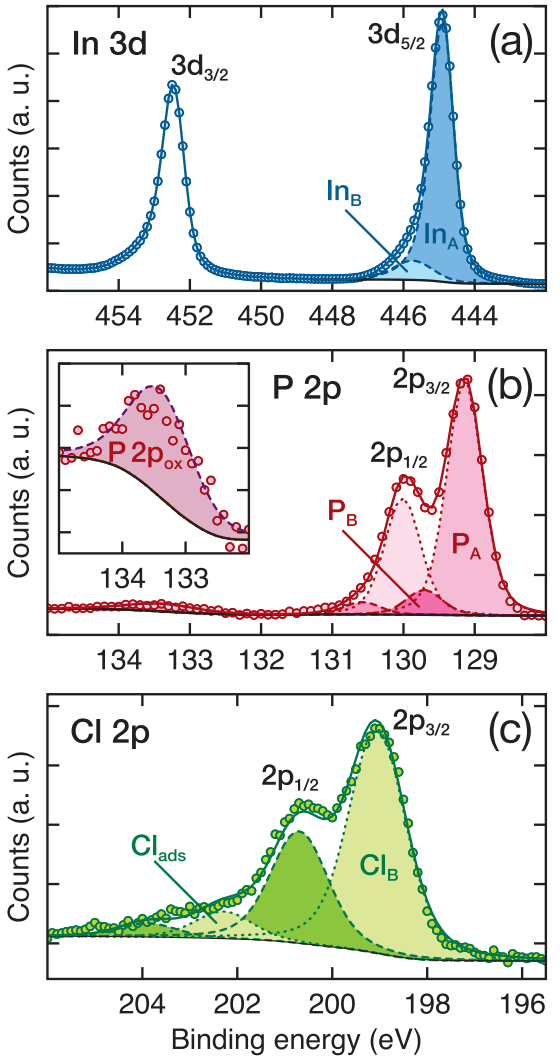

Figure 9. Reconstructions of the In $3 \mathrm{~d}_{5 / 2}$ (a), P $2 \mathrm{p}$ (b) and Cl $2 \mathrm{p}$ (c) XPS peaks obtained on $\mathrm{n}$-InP after porous etching at $5 \mathrm{~V}$. The insent in (b) presents an enlarged view of the peak $P 2 p_{o x}$ located at high energy. The annotations $\mathrm{In}_{\mathrm{A}}, \mathrm{P}_{\mathrm{A}}, \mathrm{In}_{\mathrm{B}}$ and $\mathrm{P}_{\mathrm{B}}$ refer to the text.

cate a change of the electronic distribution that occurs when a bond is established with a more electronegative specie such as $\mathrm{Cl}$. It also corresponds to the measured quantities $\left((\mathrm{In}+\mathrm{P})_{\mathrm{B}} / \mathrm{Cl}_{\mathrm{B}}=0.75\right)$. The second $\mathrm{Cl} 2 \mathrm{p}\left(\mathrm{Cl}_{\mathrm{ads}}\right)$ spin-orbit doublet at $202.3 \mathrm{eV}$ can be attributed to the presence of chlorine that has not been evacuated from the cavities $(<1$ at. $\%) .^{31}$

The $\mathrm{C} 1 \mathrm{~s}$ and $\mathrm{O}$ 1s spectral regions are presented in Fig. 10. The $\mathrm{C}$ 1s spectrum shows high organic contents and the quantity of oxygen related to the oxidation of the sample surface $\left(\mathrm{O}_{\mathrm{ox}}\right)$ is deduced by subtracting the $\mathrm{O}$ involved in the carbon superficial contamination layer $(\mathrm{C}-\mathrm{C}, \mathrm{C}-\mathrm{O}, \mathrm{C}=\mathrm{O}, \mathrm{O}-\mathrm{C}=\mathrm{O})$ after $\mathrm{C} 1 \mathrm{~s}$ reconstruction (Fig. 10a). The oxidation of the surface can be neglected because both $\mathrm{O}_{\mathrm{ox}}$ and $\mathrm{P}_{\mathrm{ox}}$ do not exceed 1 to 1.5 at.\%, attesting therefore the previous attri-

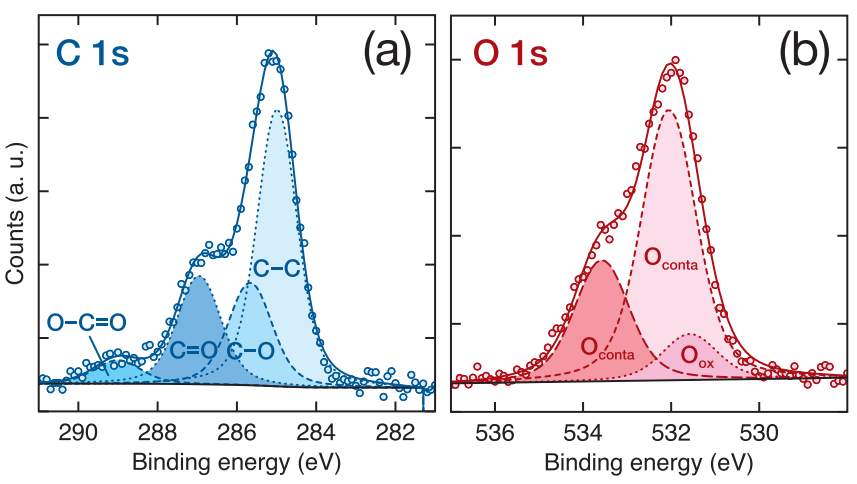

Figure 10. Reconstructions of the $\mathrm{C}$ 1s (a) and $\mathrm{O} 1 \mathrm{~s}$ (b) XPS peaks obtained on $\mathrm{n}$-InP after porous etching at $5 \mathrm{~V}$. The different contributions are annotated on the plots and refer to the text. 
butions of the high energy contributions of $\mathrm{P} 2 \mathrm{p}$ peak and especially In $3 \mathrm{~d}$ peak whose oxide contribution appears in the same region as the $\operatorname{In}_{\mathrm{B}}$ one. The main additional contributions observed in the case of porous surfaces are thus related to $\mathrm{Cl}$-containing compounds. This is in line with the expected corrosion products for InP dissolution in $\mathrm{HCl}$, i. e. $\mathrm{InCl}_{3}$. No $\mathrm{PCl}_{3}$ or $\mathrm{PCl}_{5}$ are expected because they are highly reactive with water. One can, however, suppose that the surface is covered by $-\mathrm{P}-\mathrm{Cl}$ or $-\mathrm{P}-\mathrm{Cl}-\mathrm{P}-$ terminations. The surface analysis indicates therefore that some of these dissolution products are still present at the pore surface. Nevertheless the quantitative analysis shows that the main detected signal corresponds to the InP network. Since the porous layer is much deeper than the probed thickness by spectrometer, it indicates that $\mathrm{Cl}$-containing compounds are traces on the surface while their major part has been evacuated and solubilized. This is confirmed by transmission electron microscopy observations ${ }^{19}$ indicating that the pores are filled with solid amorphous products which have not the same composition as the initial electrolyte.

Dissolution mechanism.-Depending on the experimental conditions (i. e. electrochemical parameters, electrolyte nature and concentration, crystal orientation...), several electrochemical dissolution mechanisms have been proposed for InP (see Refs in Table I). The process, in which 6 or 8 charges are involved (see Eq. 2), is however mainly proposed.

$$
\begin{array}{r}
\mathrm{InP}+x \mathrm{~h}^{+} \longrightarrow \mathrm{In}^{3+}+\mathrm{P}^{3+}\left(\text { or }^{5+}\right)+y \mathrm{e}^{-} \\
\text {with } \quad x+y=z=6 \quad \text { if } \mathrm{P}^{3+} \\
\text { or } \quad x+y=z=8 \text { if } \mathrm{P}^{5+}
\end{array}
$$

The present work, though, shows that the dissolution valence is 2 . It suggests that the dissolution process that is usually accepted for the uniform etching of InP cannot be applied to describe the pore formation. This leads to consider another dissolution mechanism. It seems that coupled and/or sequential electrochemical and chemical dissolution steps take place during the polarization. Preusser et al. ${ }^{23}$ have reported a current doubling effect during the photoelectrochemical etching of $n$-InP. They ascribed this phenomenon to an electron injection from adsorbed corrosion products to the conduction band of the semiconductor. Although such process can occur in the present case, the electron should be collected by the external electric circuit and, then, be quantified in the measured coulometric charge. Thus simultaneous process must be a pure chemical process. This phenomenon should be related to the electrochemical process because it does not maintain unlimitedly after the porous etching.

Ulin and Konnikov have described a mechanism to specifically describe the porous etching of III-V semiconductors. ${ }^{19,20}$ In their model, the authors propose that the applied voltage assists the anion adsorption at the surface. When a sufficient bias is reached, the pore formation onset ( $\Delta V \approx 1.5 \mathrm{~V}$ for $\mathrm{InP})$, the $\mathrm{Cl}^{-}$are chemisorbed on the whole InP surface, and a degenerated inversion layer is formed on the semiconductor side. A further increase of the anodic potential induces the upward shift of the levels of occupied states of the chemisorbed anions with respect to the energy band edges of the semiconductor and their approach to the conduction band levels. Under such conditions, nucleophilic substitutions occur between the adsorbed anions and the lattice atoms located in the subsurface. The reactions involve the $\mathrm{Cl}^{-}$ and the vacant antibonding $\left(s p^{3}\right)^{*}$ of nonbonding $\left(d^{2} s p^{3}\right)$ orbitals (acceptor electrophilic centers) of the coordination-saturated atoms of InP. These reactions are facilitated if they occur synchronously by the cooperative mechanism and are localized at compact areas of the semiconductor surface. The chemical bond breaking is associated to the transfer of 2 electrons to the conduction band of the semiconductor. This injection of 2 charges is consistent with the a dissolution valence of 2 . The proposed mechanism is thus in agreement with the findings of the AAS investigations as well as the XPS analyses since $\mathrm{Cl}$-containing intermediaries have been evidenced. The experimental onset for pore formation is situated in the range of $1.5 \mathrm{~V}$ for $\mathrm{CO}$ pores and the applied voltage in the case of CLO pores is, of course, much higher.

\section{Conclusions}

The dissolution valence of InP has been successfully determined from chemical analyses of the dissolved species using AAS. Depending on the applied polarization, it is known that the geometry of the pores is strongly modified. In the present study, the evolution of the amount of dissolved materials suggests, however, a continuous and similar process for both CO and CLO pores. The same dissolution valence, $z \approx 2$, is indeed found for both morphologies. The XPS analyses indicate that the corrosion products are $\mathrm{Cl}$-containning species such as $\mathrm{InCl}_{3}$ and no oxide is formed during the etching process. These results are in line with a model proposed earlier ${ }^{19,20}$ in which the porous etching is described as cooperative nucleophilic substitutions assisted by the applied voltage. A similar dissolution valence is reported but the method presented, here, allows for a direct determination while $z$ is deduced from the SEM and the electrochemical data in this previous work. It appears therefore that the combination of AAS with XPS is a valuable approach to experimentally determine the dissolution valence and identify the corrosion products of the n-InP porous etching. To our point of view, SEM observations provide critical information on the morphology as well as on the chronology of the pore growth but it can only be used to determine $z$ in the case of highly-ordered pore geometries. Nevertheless, the present study does not elucidate the morphology difference (CO and CLO) observed depending on the applied voltage on InP and some other III-V compounds. The chemical aspects of the dissolution have been emphasized, here, but the geometric features could be more related to the physical considerations of the etching phenomenon.

\section{ORCID}

Lionel Santinacci (D) https://orcid.org/0000-0002-7250-0704

\section{References}

1. L. Santinacci and T. Djenizian, C. R. Chimie, 11, 962 (2008).

2. V. Lehmann, Electrochemistry of Silicon, Wiley-VCH, Weinheim, 2002.

3. V. Lehmann, J. Electrochem. Soc., 140, 2836 (1993).

4. H. Foll, S. Langa, J. Carstensen, M. Christophersen, and I. M. Tiginyanu, Adv. Mater., 15, 183 (2003).

5. B. D. Chase and D. B. Holt, J. Electrochem. Soc., 119, 314 (1972).

6. F. M. Ross, G. Oskam, P. C. Searson, J. M. Macaulay, and J. A. Liddle, Philos. Mag. A, 75, 525 (1997).

7. T. Takizawa, S. Arai, and M. Nakahara, Jpn. J. Appl. Phys.(Part 2), 33, L643 (1994).

8. B. H. Erne, D. Vanmaekelbergh, and J. J. Kelly, J. Electrochem. Soc., 143, 305 (1996).

9. P. Schmuki, L. Santinacci, T. Djenizian, and D. J. Lockwood, Phys. Status Solidi A, 182, 51 (2000).

10. P. Schmuki, L. Santinacci, D. J. Lockwood, and M. J. Graham, Phys. Status Solidi A, 197, 71 (2003).

11. A.-M. Goncalves, L. Santinacci, A. Eb, I. Gerard, C. Mathieu, and A. Etcheberry, Electrochem. Solid-State Lett., 10, D35 (2007).

12. H. Fujikura, A. M. Liu, A. Hamamatsu, T. Sato, and H. Hasegawa, Jpn. J. Appl. Phys.(Part 1), 39, 4616 (2000).

13. C. O'Dwyer, D. N. Buckley, D. Sutton, and S. B. Newcomb, J. Electrochem. Soc., 153, G1039 (2006).

14. T. Djenizian, G. I. Sproule, S. Moisa, D. Landheer, X. Wu, L. Santinacci, P. Schmuki, and M. J. Graham, Electrochim. Acta, 47, 2733 (2002).

15. L. Santinacci, G. I. Sproule, S. Moisa, D. Landheer, X. Wu, A. Banu, T. Djenizian, P. Schmuki, and M. J. Graham, Corr. Sci., 46, 2067 (2004).

16. Z. Weng, A. Liu, Y. Sang, J. Zhang, Z. Hu, Y. Liu, and W. Liu, J. Porous Mater, 16, 707 (2009).

17. N. Quill, R. P. Lynch, C. O'Dwyer, and D. N. Buckley, ECS Trans., 50, 377 (2012).

18. P. A. Kohl, C. Wolowodiuk, and F. W. Ostermayer Jr., J. Electrochem. Soc., 130, 2288 (1983).

19. V. P. Ulin and S. G. Konnikov, Semiconductors, 41, 832 (2007).

20. V. P. Ulin and S. G. Konnikov, Semiconductors, 41, 845 (2007).

21. A. B. Ellis, J. M. Bolts, and M. S. Wrighton, J. Electrochem. Soc., 124, 1603 (1977).

22. P. H. L. Notten, J. Electrochem. Soc., 131, 2641 (1984).

23. S. Preusser, M. Herlem, A. Etcheberry, and J. Jaume, Electrochim. Acta, 37, 289 (1992). 
24. L. Santinacci, M. Bouttemy, I. Gerard, and A. Etcheberry, ECS Transactions, 19, 313 (2009).

25. R. P. Lynch, N. Quill, C. O'Dwyer, S. Nakahara, and D. N. Buckley, Phys. Chem. Chem. Phys., 15, 15135 (2013).

26. J. Carstensen, E. Foca, S. Keipert, H. Foll, M. Leisner, and A. Cojocaru, Phys. Status Solidi A, 205, 2485 (2008)

27. L. Santinacci, A.-M. Gonçalves, N. Simon, and A. Etcheberry, Electrochim. Acta, 56, 878 (2010).
28. C. O'Dwyer, D. N. Buckley, D. Sutton, M. Serantoni, and S. B. Newcomb, J. Electrochem. Soc., 154, H78 (2007).

29. D. L. Perry, Preview this Book Handbook of Inorganic Compounds, Second Edition, CRC Press, 2011.

30. J. F. Moulder, W. F. Stickle, P. E. Sobol, and K. D. Bomben, Handbook of X-Ray Photoelectron Spectroscopy: A Reference Book of Standard Spectra for Identification and Interpretation of XPS Data, Physical Electronics, Eden Prairie, Minn., 1995.

31. H. J. Lewerenz and K. H. Schulte, Electrochim. Acta, 47, 2639 (2002). 